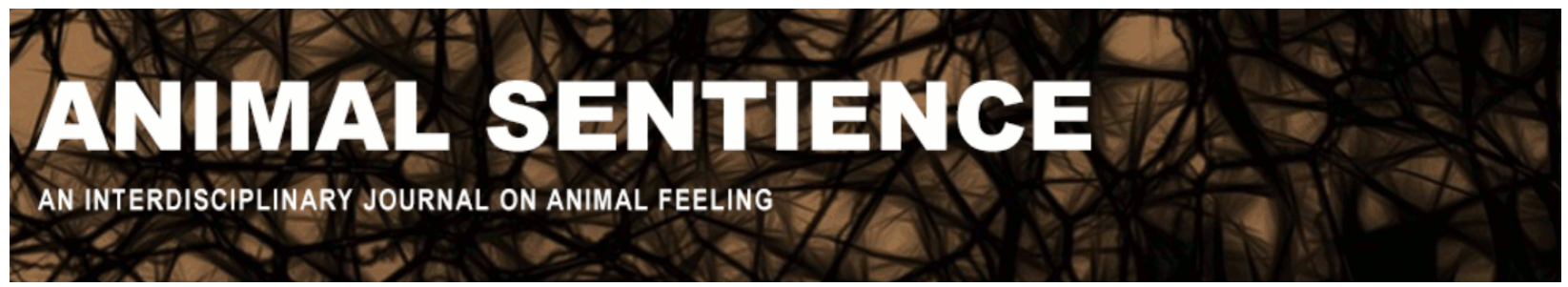

Gerlai, Robert (2020) Tribal brains in the global village: Deeper roots of the pandemic. Animal Sentience 30(24)

DOI: 10.51291/2377-7478.1655

Date of submission: 2020-11-02

Date of acceptance: 2020-11-02

(c) $\underset{\mathrm{EY}}{\mathrm{C}}$

This article has appeared in the journal Animal

Sentience, a peer-reviewed journal on animal

cognition and feeling. It has been made open access,

free for all, by WellBeing International and deposited

in the WBI Studies Repository. For more information,

please contact

wbisr-info@wellbeingintl.org.

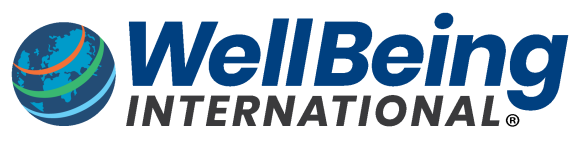

SOLUTIONS FOR PEOPLE, ANIMALS AND ENVIRONMENT 


\title{
Tribal brains in the global village: Deeper roots of the pandemic
}

Commentary on Wiebers \& Feigin on Covid Crisis

\author{
Robert Gerlai \\ Department of Psychology, University of Toronto Mississauga
}

\begin{abstract}
I briefly recap the messages of the target article by Wiebers \& Feigin (2020) and the accompanying peer commentaries about what we learn from the COVID-19 pandemic. Using the rapid evolution of viruses as an example of the importance of prevention, I explore why it is difficult for our species to foresee and prevent unintended global changes resulting from human activity. I end with a discussion about the long-term future, the ultimate problem inherent in our current mindset and the structure of our economy: growth.
\end{abstract}

Robert Gerlai is John Carlin Roder Distinguished Professor in Behavioural Neuroscience, Department of Psychology, University of Toronto Mississauga. He has received the Research Excellence Award from University of Toronto, the Distinguished Scientist Award from IBANGS and the Outstanding Achievement Award from IBNS, for which he has also served as its president. Website

1. Introduction. Our sophisticated brain, producing complex cognitive functions and social behaviours, has led to cultural evolution in which knowledge is gained, recorded and accumulates, allowing continued technological advancements. The result is rapid, unabated population growth. This growth has reached a level where we have started to affect Earth on a global scale. The COVID-19 pandemic is one result of this global anthropogenic influence.

In their eloquent and succinct target article, Wiebers \& Feigin (2020) (W\&F) make excellent points about what we learn from this pandemic. They focus on how humanity interacts with the living world and how this interaction has led to issues that not only threaten our fellow animals and their habitats but can also lead to our own demise. W\&F make concrete recommendations for actions, including banning live-animal markets, abandoning the inhumane and unhealthy practice of industry-level animal crowding in factory farms, and promoting a plant-based diet by financial means and education.

The commentaries expand this with several additional recommendations, including the need for multilevel and multidisciplinary analyses of factors underlying pandemics as well as global cooperation, integration and incentives (Morand, 2020; Fox, 2020; Schuck-Paim, 2020). Commentators also suggest revising local as well as international law and creating novel global governance structures to aid in the enforcement of standards in several contexts relevant for the COVID-19 pandemic (Whitfort, 2020; Wyatt, 2020; Lee, 2020). Commentators also discuss the specifics of how our current agricultural practices contribute to both human diseases and animal suffering (Cao, 2020; Greger, 2020; Broom, 2020; Feigin, 2020; cf. Robbins, 2020), and how such practices can be reformed by innovations such as making cultured and plant-based "meat" (Anomaly, 2020; Bryant, 2020; Lovell, 2020), and/or by abandoning misconceptions about what we should eat (Eshel, 2020). The discussion also extends to another human activity induced global threat: climate change (Fawcett, 2020). 
The commentators' recommendations are important. Their implementation should bring concrete benefits. There are also some deeper, longer ranging issues, however. These may seem only conceptual, but I would argue that they represent the root of the problems we eventually have to face. This reaches all the way down to how our societies and economies function. I will illustrate the problems using three simplistic dichotomies. But first, let me emphasize one point we all agree on: when it comes to pandemics, prevention is the key.

2. The importance of prevention in light of the rapid replication cycle of viruses. There are many reasons why prevention is crucial. Here I just mention one: the fast evolution of viruses. The SARS-CoV-2 virus is a simple biological entity. Like other viruses, it replicates quickly. At every replication, nucleotide copying errors may occur. Thus, the mutation rate per unit time is high. When SARS-CoV-2 infects millions of people, the number of different nucleotide sequence variants in the evolving viruses becomes enormous; thus natural selection will have many choices. This natural selection process results in rapidly and continually adapting strains of SARS-CoV-2, a simple mathematical certainty for which we already have empirical evidence (Shaminur et al., 2020; Badua et al., 2020). How these variants of SARS-CoV-2 will behave -whether their genetic differences will translate to novel pathogenic features and strains that can repeatedly evade immune detection and thus cause recurrent infections -- is difficult to forecast. But one thing is certain now that this virus has infected a large number of people: the genie of rapid viral evolutionary processes is out of the bottle. It would have been easier to keep it bottled up. Why did we not act sooner? The occurrence of a major pandemic was already predicted with underlying factors eerily similar to those behind COVID-19 a quarter of a century ago (e.g. Shortridge, 1995). Can pandemics be prevented at all, given our failures with this current one? Can our abuse of the living world, and the lack of respect we show toward it, ever change? Let me turn to some conceptual points illustrated by the three dichotomies below to answer these questions.

3. The conscious and conscientious mind vs instinct. Consider these (over-simplified) questions: Why do we often act against our own long-term interests? Taking the COVID-19 pandemic as an example, why could we not socially isolate longer and better? According to some, the pandemic would have been practically over after a three-week long complete lockdown.

This is a segue to some general problems with a brief exploration of an evolutionary question with some practical relevance. We are creatures with a mind that can acquire a vast amount of information and can generate complex thought. We are not devoid of genetic predispositions, however: instincts. The tribal brain of modern Homo sapiens arose about 200,000 years ago. In the 21 st century, this brain is expected to cope with global scale events that it has never encountered throughout its evolution. Changes are occurring that may not even be perceptible to us on a short time scale. Global events are unfolding that would require altruism and cooperation at a scale Homo sapiens has never encountered during its evolutionary past. Can our cognitive abilities, coupled with our culture-induced accumulation of recorded knowledge fundamentally change our tribal perspective? I believe the answer to these questions is a tempered yes. However, there are factors that work against us. Here, I continue with two principal challenges we have to face. One, the time scale on which we usually operate. Two, a thermodynamic conundrum awaiting us in the future, if we keep marching on our current path. 
4. Time scale of human interests vs. time scale of effects of human activities. The time-scale of human interests is short. Politicians tend to plan for perhaps 3-4 years ahead, rarely beyond. Private citizens as well as corporations are incentivised to behave in a way that benefits them now, perhaps in the near future, but rarely decades down the road, and almost never several centuries from now. On the other hand, the effects of our actions take longer to manifest at the global scale. Nevertheless, they can have lasting consequences that are difficult to reverse. Thus, despite clear scientific evidence to the contrary, we often do not personally feel the fact that we have altered, for example, biological evolution, ecosystems, species diversity, or the climate.

The COVID-19 pandemic is a sad reminder that this feeling of stability has been wrong. We do affect the natural world, and, in return, this new world affects us. The SARS-CoV-2 virus spread fast, and gave us an unusually rapid warning, because of its replication speed, mode of transmission (e.g. aerosols) and relatively long incubation period during which it is already infectious. Some may say this combination of features of the virus was just bad luck; that it was never inevitable. However, the handwriting has been on the wall for a long time. The factors that enabled the pandemic to occur, mentioned in W\&F's target article and in the subsequent commentaries, have all been known and discussed before. The only uncertainty about the pandemic was the specific identity of the pathogen that would create it and the exact date when it would start. Yet, politicians continued to manoeuvre, corporations continued to focus on their profit, nations quarrelled about tariffs, and individuals went about their lives enjoying their favourite foods as we were silently marching towards this catastrophe. In other words, individuals, corporations, politicians did not notice the changes that were unfolding globally, they missed the feedback.

A system without appropriate feedback mechanisms (a negative feedback loop) will go out of control. Humanity is currently such a system. How can we establish the feedback loop? W\&F's target article and the commentaries provide some clues:

(1) We know we cannot trust ourselves, as we have been inefficient in detecting and interpreting feedback on the global scale. Thus, we need to provide appropriate feedback artificially. One way to do this is to create, empower and support International and multidisciplinary organizations that are capable of collecting and analysing global data in an objective manner. Such organizations will detect and interpret the feedback that Earth is trying to give us.

(2) We are also not incentivised to act according to what is good for us in the long run. Thus, we need to adopt strict international laws and to devise ways to enforce them in the context of global scale anthropogenic effects (Treves et al. 2019). We also need to establish mechanisms globally that properly reward private citizens, politicians, corporations and nations that help humanity plan and act for the long run.

(3) We need to educate ourselves. The right choices can only be made, and the decisions can only be properly implemented, by minds that are empowered by knowledge at the grass-roots level.

5. Fundamental features of our society versus our limited space and resources. Our 21st century culture, our mindset, our economies are built on growth. Sustainability is a buzzword in several circles, but there is very little that is sustainable about practically anything we do. Global human population size has been continuously increasing. Successful nations expect to deliver continually growing GDP. Our scientists, engineers, and innovators work towards elevated production speed and efficiency. We want better, we want more. Assume that we are able to produce meat more efficiently and in a more humane manner by using cell culture 
and recombinant DNA technologies. Assume we will successfully devise means for efficient plant-based food production in towering glass skyscrapers allowing huge pieces of land to be turned back into species-diverse natural habitats. Assume we only use clean renewable energy. These innovations are not science fiction but will certainly be stunning human achievements once implemented. They will show that we take our responsibility of being a shepherd of this Globe seriously. But the ultimate problem would remain: growth is not sustainable. On the long-long haul, we will need to face the simple thermodynamic fact that energy and resource density cannot increase indefinitely in a fairly closed and spatially limited system like Earth: we will run out of space and resources. Given how slowly we change, it is a good idea for humanity to start planning.

\section{References}

Anomaly, Jonathan (2020) Cultured meat would prevent the next Covid crisis. Animal Sentience 30(5)

Badua, Christian Luke D. C.; Baldo, Karol Ann T.; Medina, Paul Mark B. (2020). Genomic and proteomic mutation landscapes of SARS-CoV-2. Journal of Medical Virology (in press) DOI: $10.1002 / j m v .26548$

Broom, Donald M. (2020) The necessity of human attitude change and methods of avoiding pandemics. Animal Sentience 30(7)

Bryant, Christopher J. (2020) Innovation in meat production: a problem and an opportunity. Animal Sentience 30(12)

Cao, Deborah (2020) Global risks of intensive animal farming and the wildlife trade. Animal Sentience 30(2)

Eshel, Gidon (2020) Pandemic leadership failures and public health. Animal Sentience 30(3)

Fawcett, Anne (2020) One Welfare, the role of health professionals, and climate change. Animal Sentience 30(9)

Feigin, Svetlana (2020) It does not cost the earth to be kind. Animal Sentience 30(13)

Fox, Michael W. (2020) One planet, one health. Animal Sentience 30(6)

Greger, Michael (2020) Whenever possible, treat the cause: Shut down the flu factories. Animal Sentience 30(4)

Lee, Kelley (2020) Rethinking global governance to address zoonotic disease risks: Connecting the dots. Animal Sentience 30(19)

Lovell, Jarret S. (2020) Plant-based diets and COVID-19: Those who harvest crops are at high risk. Animal Sentience 30(10)

Morand, Serge (2020) New approach to health and the environment to avoid future pandemics. Animal Sentience 30(14)

Robbins, Jesse (2020) Be wary of simple solutions to complex problems. Animal Sentience $30(16)$

Schuck-Paim, Cynthia (2020) Intensive animal farming conditions are a major threat to global health. Animal Sentience 30(8)

Shaminur Rahman, M; Rafiul Islam, M; Rubayet UI Alam, A S M; Islam, Israt; Nazmul Hoque, M; Akter, Salma; Rahaman, Md Mizanur; Sultana, Munawar; Anwar Hossain, M 
(2020). Evolutionary dynamics of SARS-CoV-2 nucleocapsid (N) protein and its consequences. Journal of Medical Virology (in press) DOI:10.1002/jmv.26626

Shortridge, Kennedy F (1995). The next pandemic influenza-virus. Lancet 346: 1210-1212.

Treves, Adrian; Santiago-Ávila, Francisco J.; and Lynn, William S. (2019) Just preservation. Animal Sentience 27(1)

Whitfort, Amanda (2020) China's lack of animal welfare legislation increases the risk of further pandemics. Animal Sentience 30(11)

Wiebers, David O., Feigin, Valery L. (2020) What the COVID-19 crisis is telling humanity. Animal Sentience 30(1)

Wyatt, Tanya (2020) Harm, Earth Jurisprudence and human/nonhuman relationships. Animal Sentience 30(15) 